\title{
A PRODUÇÃO DE RESUMOS ACADÊMICOS NA UNIVERSIDADE: PERCEPÇÕES DE MODELOS DE ENSINO-APRENDIZAGEM NA PERSPECTIVA DOS LETRAMENTOS
}

\author{
THE WRITING OF ACADEMIC SUMMARIES AT UNIVERSITY: \\ PERCEPTIONS OF TEACHING AND LEARNING MODELS UNDER \\ THE PERSPECTIVE OF ACADEMIC LITERACIES
}

\author{
Marta Cristina da Silva* \\ Laura Silveira Botelho** \\ Marília de Carvalho Caetano Oliveira ${ }^{* \star}$
}

\begin{abstract}
RESUMO
Este trabalho faz parte de um projeto interinstitucional e interdisciplinar que pretende analisar as práticas de escrita que envolvem o gênero resumo acadêmico na construção do software AutorlA, que tem como objetivo colaborar na produção de resumos por estudantes de graduação. Defendendo um viés social e ideológico dos letramentos (STREET, 2010a), realizamos um recorte dessa pesquisa mais ampla, com o objetivo de investigar as percepções sobre letramentos acadêmicos envolvidas na produção do gênero resumo de uma turma de primeiro semestre de Letras, tanto na visão dos estudantes quanto da professora da turma. Nossa ancoragem teórica é baseada nos Novos Estudos de Letramento - NEL (STREET, 2010a; LEA; STREET, 1998; LILLIS; SCOTT, 2007). Em termos metodológicos, realizamos uma pesquisa qualitativa de cunho interpretativista, com base nos preceitos da Linguística Aplicada. Os resultados obtidos sugerem que o ensino e a aprendizagem da produção de textos acadêmicos devem ser promovidos considerando, de modo complementar, os modelos de habilidades de estudos, de socialização acadêmica e dos letramentos acadêmicos, para que tanto a materialidade linguística quanto os aspectos sociodiscursivos sejam contemplados no processo.
\end{abstract}

Palavras-chave: letramentos acadêmicos; escrita de gêneros acadêmicos; resumo acadêmico.

\section{ABSTRACT}

This paper is part of an interinstitutional and interdisciplinary project which intends to analyse Writing practices involving the genre academic summary in the process of creating the software AutorlA, which aims at collaborating with the production of summaries by undergraduate students. Based on a social and ideological view of literacies (STREET, 2010), we have selected part of a larger research, having as an objective to investigate perceptions on academic literacies involved in the production of the summary in a class of the first term of a Letters Course, both from the point of view of the students and of the teacher. Our theoretical principles are based on the New Studies of Literacy - NSL (STREET, 2010a; LEA; STREET, 1998; LILLIS; SCOTT, 2007). Regarding methodology, principles of qualitative and interpretative research are used, following concepts of Applied Linguistics. The results achieved suggest that the teaching and learning of academic text production should be implemented by taking into account, in a complementary manner, the models of Study Skills, Academic Socialisation and Academic Literacies, so that both linguistic material traits and sociodiscursive aspects can be considered in the process.

Keywords: academic literacies; writing of academic genres; academic summary.

\section{INTRODUÇÃO}

Este trabalho faz parte de um projeto interinstitucional e interdisciplinar que pretende analisar as práticas de escrita envolvendo o gênero resumo acadêmico na construção de um software ${ }^{1}$ que tem como objetivo colaborar na produção de resumos produzidos por estudantes de graduação.

\footnotetext{
* Universidade Federal de Juiz de Fora (UFJF), Juiz de Fora, MG, Brasil. marta.silva@ufjf.br. Orcid: https://orcid.org/0000-0003-1917-1734

** Universidade Federal de São João del-Rei (UFSJ), São João del-Rei, MG, Brasil. laurabotelho@ufsj.edu.br. Orcid: https://orcid.org/0000-0003-0234-706X

*** Universidade Federal de São João del-Rei (UFSJ), São João del-Rei, MG, Brasil. mariliacarvalho@ufsj.edu.br. Orcid: https://orcid.org/0000-0002-1414-1547

1. O software AutorIA (versão 1.0) foi elaborado pelos professores Marília de Carvalho Caetano Oliveira (UFSJ/CDB), Fernando Augusto Teixeira (UFSJ/CAP), Alex Vidigal Bastos (UFSJ/CAP) e Marta Cristina da Silva (PPGL/UFJF). Compõem também a equipe os graduandos Álvaro Henrique Santos Ribeiro (Engenharia de Telecomunicações) e Matheus Cezário dos Santos (Engenharia Mecatrônica). A pesquisa foi desenvolvida no âmbito do grupo de pesquisa Letramentos, Gêneros e Ensino (LEGEN). Mais informações sobre esse software serão divulgadas tão logo obtenhamos a concessão da patente.
} 
Defendendo um viés social e ideológico dos letramentos (STREET, 2010a), realizamos um recorte dessa pesquisa mais ampla, com o objetivo de investigar as percepções sobre letramentos acadêmicos envolvidas na produção do gênero resumo de uma turma de primeiro semestre de Letras, tanto na visão dos estudantes quanto da professora da turma. Decorrentes desse objetivo geral, temos como objetivos específicos: a) verificar indícios dos modelos de escrita utilizados pelos estudantes nas entrevistas sobre os resumos acadêmicos; b) analisar em que medida a entrevista da professora expressa sua opção por determinado(s) modelo(s) de escrita.

Escolheu-se focalizar o gênero resumo pela sua importância como atividade escolar e acadêmica, muito solicitada em diversas disciplinas. Sendo assim, a produção de resumos é significativa tanto para o estudante, que pode estudar a partir dele, quanto para o professor, que a utiliza como apoio para o ensino e avaliação (NASCIMENTO, 2005). Além disso, "[...] as capacidades necessárias para a produção desse gênero são também indispensáveis para outros gêneros acadêmicos" (MACHADO; LOUSADA; ABREU-TARDELLI, 2004, p. 14).

Sabemos, porém, que a escrita acadêmica e, em particular, o resumo acadêmico, tem características bem específicas, que são diferentes dos textos com os quais, normalmente, os alunos ingressantes na universidade estão acostumados. Por isso, esses estudantes podem enfrentar algumas dificuldades no processo de aprendizagem, as quais podem estar ligadas, por exemplo, à seleção e à organização das informações mais importantes do texto original, conforme já demonstrou Caetano Oliveira (2020). Esses fatos reforçam ainda mais a necessidade de aprofundar o estudo sobre a produção de resumos acadêmicos e sobre as percepções que são construídas a partir dele, a fim de que estratégias de ensino cada vez mais adequadas possam ser construídas.

O conceito de resumo acadêmico que adotamos foi proposto por Machado (2002). A autora define resumo acadêmico como um texto que apresenta, de forma sintética, conteúdo de outro texto (artigo, livro, ensaio etc.), de outro autor, tendo como objetivos evidenciar a compreensão do texto lido e a apropriação de seus conceitos e relações, além de outros propósitos, como informar ao leitor o conteúdo da obra. Machado (2002) explica que no resumo ${ }^{2}$ mantém-se a estrutura organizacional do texto original (portanto, não há inversão da ordem de informações) e também não há traços avaliativos, tampouco adição de informações.

É importante esclarecer tal definição por causa de uma possível confusão terminológica que pode envolver esse gênero que, muitas vezes, é confundido com o fichamento (cópia dos trechos principais de outros textos), resumo/ abstract (síntese de artigo, monografia, tese, dissertação que segue as normas da ABNT), resenha (apresentação e avaliação de livros ou outros textos/atividades). São gêneros com propósitos diferentes, circulação social específica, interlocutores diversos e estrutura retórica particular. Esses são gêneros importantes, porém distintos, e que têm grande presença nas atividades acadêmicas.

Consideramos o resumo acadêmico relevante porque ele pode servir como instrumento de estudo e compreensão de textos para os estudantes e, eventualmente, para que estes demonstrem ao professor que se apropriaram do que foi lido. Na perspectiva da formação acadêmica, conforme Matencio (2003, p. 1-2), "produzir resumos e resenhas é de crucial importância na formação universitária, uma vez que, através desse tipo de atividade de retextualização - de produção de um novo texto a partir de um ou mais textos-base -, o estudante, além de registrar a leitura, manifesta sua compreensão de conceitos e do fazer-científico da área de conhecimento em que começa a atuar". Além disso, o resumo enquanto gênero é fundamental na produção de outros gêneros acadêmicos na medida em que desenvolve a capacidade de "resumir"/retextualizar em artigos, monografias, ensaios, dissertações, teses, resenhas.

Dessa forma, ao se referir ao processo de retextualização, a autora assevera que, se esse mecanismo transforma um texto em outro, isso implica, necessariamente, "mudança de propósito, porque não se trata mais de operar sobre o mesmo texto, para transformá-lo - o que seria o caso da reescrita -, mas produzir novo texto" (MATENCIO, 2002, p. 113).

Em suma, pela retextualização, produzimos um novo texto a partir de novos paradigmas contextuais, já que redimensionamos "as projeções de imagem dos interlocutores, de seus papéis sociais e comunicativos, dos conhecimentos partilhados, assim como de motivações e intenções, de espaço e tempo de produção/recepção, de atribuir novo propósito à produção linguageira" (MATENCIO, 2002, p. 113).

Levando em consideração todos os aspectos mencionados, este artigo se estrutura da seguinte forma: a seguir, apresentamos nossa ancoragem teórica, baseada nos Novos Estudos de Letramento - NEL (STREET, 1984, 2003,

2. Neste artigo, para nos referirmos ao gênero resumo acadêmico a partir da definição de Machado (2002), ora usaremos "resumo acadêmico", ora usaremos "resumo", mas sempre nos referindo ao mesmo gênero e ao mesmo conceito. 
2014; LEA; STREET, 1998; LILLIS; SCOTT, 2007). Conceitos como letramento autônomo e ideológico serão abordados, assim como a vertente teórica dos Letramentos Acadêmicos e os modelos de escrita propostos por Street (2010a). Nossa proposta metodológica aparece na seção seguinte: realizamos uma pesquisa qualitativa de cunho interpretativista, com base nos preceitos da Linguística Aplicada. Nossa análise de dados emerge das entrevistas de alunos e da professora da turma do primeiro semestre do curso de Letras. Nossas considerações finais fecham o artigo, em que propomos que o ensino e a aprendizagem da produção de textos acadêmicos devem ser promovidos considerando, pelo menos, três perspectivas complementares, para que tanto a materialidade linguística quanto os aspectos sociodiscursivos sejam contemplados no processo.

\section{PERSPECTIVAS TEÓRICAS DOS ESTUDOS DE LETRAMENTOS}

Neste trabalho, partimos do pressuposto de que a escrita é uma cultura e não uma habilidade meramente técnica. Por isso, a produção de textos só pode ser concebida num contexto de experiências que promovam sentido, evidenciando ao aluno como funciona essa tecnologia na sociedade.

Assim, consideramos que a produção de texto precisa estar atrelada às mais diversas atividades sociais e que, além da estrutura ou das regras gerais que são constitutivas de um dado gênero textual/discursivo, é necessário que o aluno compreenda os usos sociais e o valor político e ideológico da ação de escrever.

A concepção de escrita como uma cultura tem como ancoragem teórica os Novos Estudos de Letramento desenvolvida pelo antropólogo Brian Street, a partir da publicação de seu livro Literacy in theory and practice, de 1984. Essa obra foi seminal para os estudos de letramento porque rompeu com a corrente de pensamento que dominava à época e que defendia a supremacia da escrita, a visão dicotômica entre oralidade e escrita e a legitimação das formas de escrita das classes dominantes. Entre as contribuições dos Novos Estudos do Letramento está a visão de que as práticas de letramentos não são neutras e estão envolvidas em processos sociais, históricos e culturais. Além disso, Street (1984) defende que os letramentos são múltiplos, ou seja, não há apenas um tipo de letramento, aquele legitimado socialmente, mas há tantos letramentos quantos forem os contextos sociais nos quais a língua escrita se inscreve (STREET, 1984).

Street $(1984$; 2003) postulou dois modelos de letramento: o autônomo e o ideológico. De acordo com o autor, o letramento autônomo está vinculado às concepções tradicionais mencionadas acima: entendem os letramentos como algo neutro e universal. Como um aparato cognitivo, as práticas de leitura e escrita são individuais, por isso, autônomas. Sendo assim, a escrita, nessa concepção, significa o domínio de uma técnica, que pode ser usada em qualquer contexto.

Como contraponto a essa concepção autônoma dos letramentos, Street (2003) defende o modelo ideológico, em que os letramentos são vistos como uma prática social e não uma técnica. Nesse sentido, as práticas letradas são permeadas de ideologia, política e relações de poder. O autor destaca, nessa dimensão social, o caráter situado dos letramentos, pois "as particularidades das práticas de leitura e escrita, que são ensinadas em qualquer contexto, dependem dos aspectos da estrutura social e do papel das instituições de ensino" (STREET, 1984, p. 8).

Embora esses conceitos sejam bastante discutidos na literatura especializada, consideramos importante retomálos aqui, pois contribuirão para a análise de dados da pesquisa. Como veremos à frente, a perspectiva autônoma não está presente apenas no discurso de professores, mas também dos estudantes, evidenciando que, de certa forma, ainda há muitos mitos relacionados à leitura e à escrita no Ensino Superior.

A seguir, apresentaremos um panorama de conceitos ligados à vertente teórica Letramentos Acadêmicos, que também darão suporte à análise.

\subsection{Contribuições dos Letramentos Acadêmicos}

Neste tópico, debateremos sobre alguns conceitos basilares que envolvem a abordagem dos Letramentos Acadêmicos à luz dos Novos Estudos de Letramentos. Street (2010a) defende que há algumas tradições que permeiam as práticas de escrita no Ensino Superior e retoma o estudo de Lea e Street (1998) para apresentar três principais modelos acerca do processo de ensino-aprendizagem na academia: habilidades de estudos, socialização acadêmica e letramentos acadêmicos. 
Esses três modelos propostos pelos autores foram usados por nós como eixos de análise das entrevistas realizadas com alunos e a professora do primeiro semestre do curso de Letras sobre a produção do resumo acadêmico.

O modelo babilidades de estudo, de acordo com Street (2010a), ancorado por uma perspectiva autônoma do letramento, compreende que a escrita se resume a um conjunto de habilidades individuais e cognitivas que o estudante precisa dominar para transpor ao meio acadêmico. Com base teórica vinda do Behaviorismo, nesse modelo, as dificuldades de leitura e escrita são vistas como um problema individual, quase uma patologia. A visão de texto, cujas análises são vistas de forma estrutural e instrumental, é bastante limitada, com enfoque na superfície do texto, dando grande importância para questões ortográficas e gramaticais.

O segundo modelo, socialização acadêmica, tem um olhar mais sensível às práticas de leitura e escrita, mas ainda com uma forte tendência de integração do discente em uma nova cultura da qual ele deve se apoderar. Desconsiderase, portanto, as práticas de letramentos pregressas dos sujeitos, pois, na socialização acadêmica, acredita-se que a cultura acadêmica é homogênea e deve ser apropriada pelos estudantes. Para Street (2010b, p. 545), esse modelo "pressupõe que os alunos precisam ser aculturados nos discursos e gêneros de disciplinas específicas, cujas características e exigências, caso sejam explicitadas aos alunos, terão como resultado o êxito destes como escritores".

Já o modelo de letramentos acadêmicos compreende os letramentos como práticas sociais, e a escrita é concebida como uma cultura, portanto. Street (2010b, p. 545) defende que esse modelo tem por foco "a construção de sentidos, identidade, poder e autoridade, e coloca em primeiro plano a natureza institucional do que conta como conhecimento em qualquer contexto acadêmico específico".

Por ser socialmente orientada, a escrita acadêmica não deve ser analisada apenas no âmbito textual, mas sim como uma forma de construção de conhecimento de atores socialmente situados. As universidades são tomadas como lugares constitutivos de identidades em que se valorizam os significados sociais das práticas linguísticas (BOTELHO et al., 2018). Essa proposição é fortalecida por Lillis e Scott (2007, p. 10) ao defenderem que, nos letramentos acadêmicos, a "prática tem primazia em relação ao texto". Em nossa pesquisa, buscamos relacionar as percepções de alunos e da professora sobre as práticas de letramento na produção do gênero resumo, por isso, consideramos que ouvir os participantes é primordial para compreendermos as práticas de escrita no contexto investigado.

Como já discutido em trabalhos anteriores (BOTELHO et al., 2018; BOTELHO; SILVA, 2014), o objetivo de descrever os três modelos mencionados acima é compreender mais profundamente a escrita dos alunos e o processo de ensino-aprendizagem no meio acadêmico. Tais modelos não têm características rígidas e dicotômicas, ao contrário, devem ser vistos como complementares, pois "são úteis para pesquisadores que buscam melhor compreender a escrita e outras práticas de letramento em contextos acadêmicos e também para educadores que desenvolvem currículos,

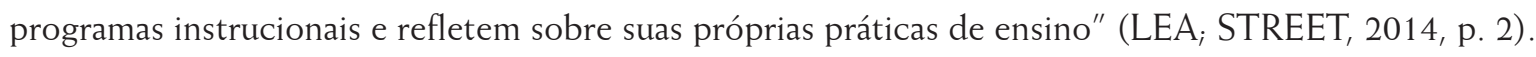

Street (2010a) também defende que é necessário, nos letramentos acadêmicos, envolver variadas práticas comunicativas, os gêneros e os campos disciplinares. Russell et al (2009), em artigo que retoma o percurso teórico dos letramentos acadêmicos, enfatizam que cada um dos modelos apresentados tem uma concepção de gênero correspondente. Nas habilidades de estudos, o gênero está relacionado às suas características formais e estruturais; já na socialização acadêmica, a percepção sobre gêneros articula-se às normas de cada campo disciplinar. Nos letramentos acadêmicos, os gêneros são vistos como uma forma de ação social. Embora não sejam desconsideradas as demandas do campo disciplinar, as práticas sociais são centrais.

Nesse sentido, deve-se mostrar a estrutura de um gênero acadêmico ainda desconhecido pelo aluno, sendo igualmente importante ressaltar como o campo disciplinar compreende os propósitos dos gêneros e como circulam socialmente. $\mathrm{O}$ que não se pode negligenciar, e isso ainda é muito comum da academia, são as práticas sociais que envolvem a produção desses textos, as relações de poder e ideologias envolvidas, as dimensões ocultas que permeiam a produção acadêmica e precisam ser explicitadas e problematizadas aos membros menos experientes.

Dito isso, passaremos ao nosso percurso metodológico e às análises das entrevistas, focalizando a visão dos participantes sobre o processo de escrita de resumos acadêmicos.

\section{PROCEDIMENTOS METODOLÓGICOS}

Neste recorte, buscamos investigar as percepções sobre letramentos acadêmicos envolvidas na produção do gênero resumo, tanto na perspectiva dos estudantes quanto da professora da turma. 
Trata-se de uma pesquisa qualitativa de cunho interpretativista (CELANI, 2005). Segundo a autora, nesse tipo de pesquisa, a intersubjetividade é um aspecto proeminente, e os significados vão sendo construídos a partir de uma abordagem dialógica entre pesquisador e participantes, considerando que estes têm papel ativo na pesquisa, tornando-se parceiros. Embora diferente do paradigma positivista, na pesquisa qualitativa também se mantém a confiança, a honestidade e a qualidade na compreensão dos dados. Antes de o trabalho ser iniciado, os voluntários explicitam seu consentimento em participar, e o pesquisador deve apresentar seus objetivos, deixando que todos se sintam à vontade para desistirem a qualquer tempo. Considerando esses procedimentos, coadunamos com Celani (2005, p. 109), quando defende que, "se a vida social é dialógica, o método para descrevê-la também deve ser dialógico". Dessa forma, acreditamos minimizar o caráter opressivo que pode afetar os participantes, considerando que essa opressão é decorrente de relações assimétricas de poder.

A partir dessa perspectiva, selecionamos como participantes de pesquisa 7 alunos que ingressaram no curso de Letras de uma universidade pública no interior de Minas Gerais, no primeiro semestre de 2019, e a professora da disciplina de gêneros acadêmicos da referida turma. A idade desses estudantes, à época, variou entre 18 e 31 anos. Com exceção de uma estudante, todos cursaram o Ensino Médio em escola pública e dois estudantes já haviam cursado outra graduação (Jornalismo e Conservação e Restauro).

A professora, por sua vez, é doutora em Estudos Linguísticos e possui ampla experiência no magistério superior (17 anos). Desde 2014, trabalha na instituição, atuando em cursos de graduação e na Pós-Graduação em Letras.

A seguir, apresentaremos o detalhamento de todos os procedimentos metodológicos realizados, a fim de que as estratégias para obtenção das entrevistas sejam contextualizadas no universo maior da pesquisa. Dado o escopo deste artigo, focalizaremos as entrevistas na análise dos dados.

Primeiramente, a docente solicitou uma primeira produção à turma, antes de o resumo acadêmico ter sido estudado em profundidade. Nesse primeiro momento, 31 textos foram produzidos (individualmente) a partir do artigo "Gêneros textuais acadêmicos: reflexões sobre metodologias de investigação", de Antônia Dilamar Araújo.

Posteriormente, depois de os alunos terem estudado a unidade sobre resumo acadêmico, a professora solicitou uma segunda produção, que foi desenvolvida a partir do artigo "A escrita no contexto dos usos linguísticos: caracterizando a escrita", escrito por Luiz Antônio Marcuschi e Judith Hoffnagel. Nessa etapa, foram produzidos 22 resumos ( 7 individuais e 13 em duplas, já que a professora havia apresentado essas opções). No presente trabalho, consideramos apenas as produções que haviam sido escritas individualmente.

Sendo assim, considerando os parâmetros anteriores, selecionamos 7 produções, tornando possível iniciarmos as entrevistas semiestruturadas com os estudantes que haviam produzido os resumos e com a professora. Fizemos a opção pela entrevista semiestruturada porque ela não apresenta a rigidez de um questionário e também porque possibilita espaço para a discussão. Dessa forma, durante a entrevista, puderam surgir novas questões relevantes sobre o tema, ampliando ainda mais a perspectiva das análises.

Para participar das entrevistas, convidamos os 7 estudantes que haviam produzido individualmente os resumos, mas apenas 6 compareceram. Após o trabalho com os alunos, convidamos também a professora da turma para ser entrevistada, e a docente prontamente atendeu ao convite ${ }^{3}$.

\section{ANÁLISE DAS ENTREVISTAS}

É importante ressaltar que aqui trataremos os modelos de letramentos acadêmicos como uma categorização para fins de análise, compreendendo, porém, que, muitas vezes, há uma linha tênue entre um modelo e outro, ou uma superposição de modelos. Também não se pode perder de vista que muitas concepções que os alunos assumiram na entrevista não foram formadas no Ensino Superior. São, antes, resultado do conhecimento acumulado ao longo dos anos de escolarização, visões arraigadas que influenciam suas práticas de letramentos até na universidade e que poderão ser ressignificadas (ou não) de acordo com suas vivências nesse novo contexto.

\subsection{Análise das entrevistas com os estudantes}

Nos excertos abaixo, buscaremos identificar a que modelo de letramentos acadêmicos os estudantes e a professora da turma pesquisada mais se alinham. Foi feita uma seleção dentre as respostas dos 6 (seis) estudantes entrevistados, no sentido de evidenciar as visões de letramentos subjacentes. Embora, em termos quantitativos, a

3. Todos os participantes da pesquisa assinaram o Termo de Consentimento Livre e Esclarecido do projeto que foi aprovado no Comitê de Ética da instituição. 
amostragem seja pequena, acreditamos que as reflexões aqui suscitadas, num viés qualitativo interpretativista, possam contribuir para generalizações acerca da forma como gêneros acadêmicos, a exemplo do resumo, têm sido tratados na universidade. Apresentaremos, inicialmente, as entrevistas dos alunos.

\subsubsection{Habilidades de estudo}

Elencamos, a seguir, exemplos que demonstram que o modelo das habilidades de estudo está muito presente nas percepções dos estudantes sobre o que é importante para produzir adequadamente um resumo acadêmico. Em alguns momentos, os estudantes parecem encarar suas dificuldades na escrita acadêmica como déficits da sua própria formação:

ENTREVISTADORA: Você se sente preparado para fazer um bom resumo?

ESTUDANTE 2: A minha escrita acadêmica é bem ruim, tanto é que eu ingressei novamente na Faculdade justamente por conta dessa defasagem que eu tive da primeira graduação.

A estudante 5 também não se sente preparada para produzir um resumo e justifica que isso se deve à forma de produzi-lo no Ensino Médio em comparação com o Superior:

ESTUDANTE 5: Não, não me sinto preparada [...] tem gente que chega direto do Ensino Médio, então, pessoas que chegam direto do Ensino Médio, resumos que são produzidos no Ensino Médio não têm nada a ver com resumo que é daqui da academia. Então, o aluno, na hora de reproduzir, ele não vai, ou então ele não entendeu, né, a teoria do negócio ali... aí ele vai e faz um processo de repetição do que ele fazia no Ensino Médio. [...].

Os resumos produzidos no Ensino Médio "que não têm nada a ver" com o que é requerido na universidade, nas palavras da aluna, revelam um estranhamento com os textos de natureza acadêmica e com tudo o que implica agir socialmente nesse novo contexto. Segundo Bezerra (2015), o estudante sente a necessidade de construir uma identidade social no decorrer da graduação que lhe permita se inserir nesse novo ambiente: "Institucionalmente falando, outros atores nesse ambiente, especialmente professores, cultivam uma série de expectativas sobre quem é e como deve agir o estudante no que diz respeito às práticas típicas da academia [...]" (BEZERRA, 2015, p. 61).

Apesar de essa estudante não se sentir preparada, demonstra, na teoria, conhecer aspectos do gênero resumo acadêmico:

ENTREVISTADORA: Quais são os elementos de um bom resumo?

ESTUDANTE 5: Um bom resumo eu acho que precisa conter a ideia central do texto que tá resumindo, a posição que o autor assume também junto com essa ideia central, qual é o objetivo daquele texto principalmente nesses resumos acadêmicos, que normalmente a gente resume um artigo e tal. A pergunta ali principal de um artigo eu acho que é bom ter no resumo até para despertar o interesse do leitor e aí a pergunta, a resposta também, a conclusão, resultados daquele artigo... eu acho que é o essencial que precisa ter é o meio, começo e fim, para mim seria esse de um resumo.

A aluna refere-se a aspectos importantes, como posição do autor, propósito do texto e destinatário, já avançando para uma percepção de socialização acadêmica. Conclui, entretanto, que o essencial é "começo, meio e fim", o que demonstra uma preocupação maior com os aspectos estruturais e a composição textual do resumo. Não chega ao ponto de considerar apenas a superfície textual, como é característico do modelo de habilidades de estudos, mas percebe-se que esse é o ponto proeminente na sua visão.

Essa mesma ideia de que é sobretudo a estrutura do texto que define o gênero, o que se relaciona bastante com a concepção de uma redação tipicamente escolar, também se encontra neste excerto:

ENTREVISTADORA: O que para você caracteriza um resumo? Que elementos ele tem que ter para ser considerado bom?

ESTUDANTE 7: Primeiro tem que ser compreensível sem o texto original, que é até uma coisa que a Professora colocou várias vezes na aula, e ele tem que ter todos os elementos que o texto original traz. Então, tipo, a parte de introdução, a do desenvolvimento e ele tem que ter um fechamento também, que fecha o resumo, mesmo.

ENTREVISTADORA: Mais alguma coisa?

ESTUDANTE 7: Não. 
A partir do trecho destacado, podemos perceber que as práticas acadêmicas estão relacionadas aos letramentos escolares e aos modelos ensaísticos de escrita com "introdução, desenvolvimento e conclusão", que têm, de maneira geral, orientações bem vagas ("início, meio e fim") e estruturais. Pasquotte-Vieira (2014, p. 168) define dissertação escolarizada como "produções escolares que buscavam se sustentar na visão canônica de escrita baseada em 'fórmulas' ou 'técnicas' e em uma lógica impessoal, repetindo, assim uma tradição de letramento baseada em textos clássicos [...] identificada como modelo ensaístico". Embora a produção de modelo ensaístico não constitua um problema, percebe-se que está vinculada a uma concepção de escrita "universal" e autossuficiente, afastando-se, portanto, de uma visão de gênero como uma forma de ação social em que se deve levar em conta, na produção e recepção, fatores sociais, históricos e culturais localmente construídos.

Além dessas questões, alguns estudantes encaram a atividade de produção de um gênero como resultado de prática, de repetição. Parecem desconsiderar os propósitos comunicativos desse gênero na universidade, tomando a produção em si mesma como finalidade e não como uma prática social:

ENTREVISTADORA: [...] o que o professor poderia fazer pra ajudar em suas dificuldades na produção de resumos?

ESTUDANTE 4: Eu acho que treino, pordue resumo é treino, tudo que é escrita é baseada em treino, e eu acho que se cobrasse mais resumos pra quem tem dificuldade ajudaria a melhorar. Colocando em destaque os problemas que são repetitivos etc.

ENTREVISTADORA: Você sabe quais os objetivos, ou seja, o para quê que você produziu os resumos aqui na Universidade?

ESTUDANTE 1: Eu acho que épra aprender como é que faz. Entender como é que funciona o resumo, mas igual ao que parece no início do artigo eu não sei se é a mesma coisa, se é tão reduzido assim, mas síntese foi o que a gente mais fez na aula da professora.

ENTREVISTADORA: Então vocêfez (o resumo) meio que sem saber para quê?

ESTUDANTE 1: Porque foi mais porque ela [a professora] estava pedindo, acho que é pra treinamento mesmo, mas en ainda não vi um lugar que está usando esse resumo no mesmo formato que a gente fez a atividade.

Aqui também se percebe claramente a aderência ao modelo de habilidades de estudos. Conforme sintetiza Bezerra (2012, p. 251), "não há, nessa abordagem, nenhum destaque para os aspectos sociais envolvidos no processo de escrita ou mesmo para as peculiaridades da escrita em cada campo disciplinar e sim para traços formais como a estrutura gramatical e a pontuação, por exemplo". Nesses excertos, a ideia recorrente de treino, de adestramento para escrever "bem" um resumo, aproxima-se muito da concepção de letramento autônomo, na crença de desenvolvimento de uma habilidade individual e cognitiva que irá assegurar o sucesso na produção.

A mesma estudante que acredita ser capaz de produzir resumo não reconhece que o resumo acadêmico possa ter usos sociais dentro do espaço situado de ensino na universidade, possivelmente por essa questão não ter sido topicalizada em aula, e ser efetivamente parte de suas práticas letradas para além de uma tarefa de escrita a ser avaliada pela professora:

ENTREVISTADORA: E você usa [o resumo] como ferramenta de estudo? Você retoma os textos?

ESTUDANTE 6: Não, para estudo eu prefiro tópicos, que aí eu vou colocando os tópicos que eu geralmente acho importantes, que acaba sendo resumo, mas não tem aquela formalidade. Não seria assim, introdução, desenvolvimento e conclusão, que teria que ter no resumo. Quando eu vou estudar, eu vou pegando tópicos e vou anotando o que eu acho importante.

Novamente, prevalece a preocupação com a infraestrutura textual do resumo ("introdução, desenvolvimento e conclusão"). A opção pelos tópicos é legítima, dependendo da situação de produção, mas parece faltar a visão do resumo como um instrumento de estudo e de outras funções sociais que a produção e leitura desse gênero possam desempenhar dentro da esfera acadêmica.

E, ainda, alguns estudantes deixam transparecer que o aprendizado da escrita acadêmica se resume ao aprendizado de algumas técnicas e normas gramaticais:

ENTREVISTADORA: E qual é sua expectativa com relação ao curso?

ESTUDANTE 2: É justamente melhorar a gramática, eu sinto bastante falta disso na Letras, porque por mais que a gente tenba o conceito de que não existe o português certo, não existe português errado, porque a lingua é viva, ainda assim a regra é básica, e a regra que você traz do 
Ensino Médio ela é extremamente defasada, porque a conceituação é errônea tem hora. Às vezes eu me questiono isso, a gente tem uma ideia de aplicabilidade da língua ao invés da funcionalidade técnica dela mesmo. Então tem bora que falta isso. Aí, por exemplo, no meu caso relativo ao resumo, é justamente isso, a funcionalidade técnica daquilo eu não domino e isso me prejudica, isso me incomoda, é uma coisa que eu estou tentando desenvolver, a passos de formiga, mas está indo".

Nesse caso, acreditamos que o foco precípuo em aspectos formais tenha conduzido esse estudante a um questionamento equivocado, pois considera que, no Ensino Médio, deveria ter aprendido aspectos de "funcionalidade técnica" em vez da "aplicabilidade da língua". O que esperamos, na verdade, é que essas duas perspectivas sejam complementares e que ainda estejam alinhadas a uma discussão sobre aspectos políticos, históricos e ideológicos na produção dos textos.

Em resumo, todas essas percepções enquadram-se na perspectiva do modelo de habilidades de estudo porque essa perspectiva, considerada mais superficial, encara os letramentos como um conjunto de habilidades individuais que os estudantes devem aprender e que, uma vez aprendido, pode ser transferido para outros contextos de uso. Objetiva consertar os déficits de aprendizagem dos estudantes, entendendo a escrita como técnica e instrumental.

\subsubsection{Socialização Acadêmica}

Os alunos também manifestaram outros tipos de percepções. Uma delas é a preocupação de seguirem as normas técnicas e usarem uma linguagem adequada ao parafrasear os autores do texto original e introduzir citações, ou seja, de estarem atentos a aspectos formais próprios do meio acadêmico:

\section{ENTREVISTADORA: Que orientações foram dadas para a elaboração do resumo?}

ESTUDANTE 1: O resumo, ela passou a orientação depois de já ter pedido alguns já. Foi mais ou menos isso, porque o resumo normal ela não passou nenbuma orientação muito, assim, não, ela deu uma explicada em normas da ABNT primeiro e citação, referência, mas esse ela não passou muito, assim, não. Ela ensinou mais foi o fichamento e a resenba. [...] Tem a questão da norma da ABNT, mas com o tempo vai acostumando com elas, mas a parte de ter que usar outros verbos pra explicar o que o autor estava querendo dizer, não ficar repetindo muito eles, é mais isso que en tive dificuldade no início.

Podemos ressaltar, na fala do estudante 1, a referência a diferentes gêneros textuais do universo acadêmico, como fichamento e resenha. Esse é um dado relevante, pois sabemos que o ensino norteado pela noção de gênero abre um horizonte para se pensar na produção de texto como uma prática social, aproximando-se do modelo de letramentos acadêmicos, que toma como central o conceito de gêneros textuais. Embora tenhamos características relativamente estáveis constituintes de cada gênero, trabalhar com ensino-aprendizagem de escrita acadêmica requer levar em conta esse local situado no qual ela se dá (quem escreve, para quem se escreve, com que propósitos e em que campo disciplinar). Seria importante considerar as situações de produção, recepção e circulação do texto produzido. O comentário da aluna, entretanto, traz uma visão homogênea de gênero, o que talvez seja o reflexo da abordagem apresentada em sala de aula.

Além dessa manifestação, outros estudantes trouxeram à tona outros gêneros em comparação ao resumo, demonstrando um certo conhecimento relativo não apenas a aspectos linguísticos, léxico-gramaticais, ou estruturais, como seria esperado no modelo de habilidades de estudos, mas também alguma noção a respeito do conteúdo temático e dos propósitos comunicativos:

ENTREVISTADORA: Você conbece outros tipos de resumo, sem ser esse que você aprendeu?

ESTUDANTE 7: Acho que não, dentro do resumo a gente sabe que tem um resumo mais uma síntese e um resumo mais completo. Acho que fora disso já deixa de ser resumo, já vai para uma resenba ou para alguma outra coisa.

ENTREVISTADORA: E qual seria a diferença entre síntese e resumo completo?

ESTUDANTE 7: a síntese seria um apanbado bem geral do que o texto fala. O resumo seria com algumas características importantes do texto, assim, um pouco mais aprofundado, mas não tanto quanto texto original.

Como observado acima, os alunos trazem consigo histórias de letramentos pregressas e fazem associações daquilo que já conheciam com o que é novo e orientado por normas que vão sendo apropriadas ao longo de 
sua trajetória acadêmica. Por isso, consideramos importante compreender os significados que os estudantes vão construindo sobre suas práticas de leitura e escrita como uma ação no mundo, como algo que pode, de fato, ter um propósito. Já para o professor, tal perspectiva pode permitir que se (re)pensem as práticas pedagógicas a serem propostas, considerando os conhecimentos, as bagagens e as vivências trazidas pelos alunos.

Uma análise meramente textual não alcança questões que são fundamentais para uma perspectiva de letramentos acadêmicos como relações de poder e identidade. Fiad (2017, p. 207) ressalta que a interpretação dessas práticas "é orientada por questões epistemológicas envolvendo as relações que os sujeitos estabelecem com o conhecimento, as relações de poder envolvidas na produção e divulgação do conhecimento e as questões de identidade". Assim, ouvir os alunos e buscar compreender suas relações com as atividades ligadas à leitura e à escrita vai além de uma avaliação do produto; considera-se, também, o processo.

No exemplo abaixo, percebe-se também a preocupação do estudante em se adequar ao contexto acadêmico (escrever de acordo com as expectativas do professor ou "grupo científico"). Quando ele diz que "isso tem uma carga", pode-se interpretar como a necessidade de ser bem aceito e bem avaliado pela comunidade discursiva da qual começa a fazer parte ao ingressar na universidade ou num determinado campo disciplinar:

ENTREVISTADORA: Sua escrita é afetada quando você sabe que seu resumo será avaliado?

ESTUDANTE 2: [...] um certo pânico, um certo receio do que eu tô fazendo não tá certo, eu tenbo que escrever para esse público, eu tenbo que escrever pra linguagem que o meu professor on que o grupo científico vai analisar. Então isso tem uma carga. Pra mim, tem uma carga de peso muito alta. Incomoda. Eu me sinto um ponco incomodado.

Na verdade, esse estudante, especificamente, já havia cursado Jornalismo, mas sabemos que cada área de conhecimento pode ter as suas especificidades mesmo em se tratando do mesmo gênero textual e, por isso, o conhecimento adquirido em uma dada área não é transferido automaticamente para outra. Como estudos já apontaram, há práticas discursivas próprias que são adotadas em contextos disciplinares específicos: "a apropriação do mesmo gênero textual em cada disciplina responde à organização epistemológica da área de conhecimento, evidenciando-se assim as conexões entre texto e contexto de produção" (MOTTA-ROTH, 2000, p. VI).

Lea (2006, p. 292) defende que escrever é parte da aprendizagem, não sendo somente um modo transparente de representação que traz consigo conteúdo: "o próprio ato de escrever constrói substancial conhecimento disciplinar. Em relação aos alunos escritores, este processo de construção do conhecimento por meio da escrita ocorre na arena da avaliação". Percebemos, portanto, que, ao pensar nos interlocutores (professor, grupo científico), o estudante relaciona-os à avaliação e isso "incomoda". Na perspectiva da socialização acadêmica, muitas vezes, há um processo de aculturação do sujeito, exigindo uma incorporação de determinadas práticas acadêmicas, nem sempre explicitadas pelos pares mais experientes.

Outra estudante tem uma posição semelhante quanto aos campos disciplinares:

ENTREVISTADORA: E dificuldades quanto à leitura dos textos acadêmicos, você tem? Se você tem, me fale quais?

[A estudante fala sobre suas experiências em um curso superior que bavia cursado num Instituto Federal.]

ESTUDANTE 7: [...] quando en comecei esse outro curso, en tive uma estranbeza nos artigos, mas acho que os artigos voltados para Letras são um pouco mais complexos também, porque já tem toda essa preocupação com a lingua, com a gramática, e que textos de outras áreas, às vezes, não têm. Então, às vezes são textos mais complicados de entender um pouco, mas teve um livro que eu peguei da outra área que eu não consegui ler, que era até para a monografia, eu tive que pedir para falar com a orientadora que eu não estava entendendo e não ia adiantar.

A estudante tem a compreensão de que há especificidades no âmbito dos letramentos acadêmicos. A expressão "estranheza nos artigos" revela sua percepção de que mesmo muitos anos de escolarização e de desenvolvimento de suas práticas letradas não assegura que se possam transferir os conhecimentos adquiridos mecanicamente para a leitura e compreensão de textos acadêmicos. Daí a importância de se tomarem os gêneros acadêmicos, seja para a leitura ou para a produção escrita, como objetos de ensino. Sem entrar no mérito do que a estudante ressaltou como características de um texto na área de Letras, fica clara, também, a ideia de que cada campo disciplinar tem suas convenções próprias dentro de um mesmo gênero, o que não compromete a estabilidade do gênero, mas destaca justamente a sua maleabilidade, a sua "estabilidade relativa", nas palavras de Bakhtin (1952/1992). 
Em comparação ao modelo de habilidades de estudos, o modelo de socialização acadêmica, por estar focado na aprendizagem e em aspectos da cultura acadêmica, mostra-se um pouco mais sensível às dificuldades enfrentadas pelos estudantes quando chegam ao ensino superior e se veem obrigados a ler e produzir textos num contexto para o qual não foram preparados. A seguir, a estudante revela de forma muito precisa (e angustiante) esse sentimento de inadequação à Academia:

\section{ENTREVISTADORA: [...] Como o professor poderia atuar para colaborar com os alunos na aprendizagem?}

ESTUDANTE 6: "Bom, pra mim assim o que pesou mesmo nesse período assim da Faculdade foram os termos que eram muito técnicos. Eu não tinba contato com isso porque no Ensino Médio, Fundamental, eu acho que é muito foco em Enem, Enem, Enem... Então, assim, a gente não tem nenbum contato com texto, assim. Então, a bora que eu peguei, eu falei: Meu Deus, que que tô fazendo aqui, não épra mim. (...), é uma coisa que tem que vir do Ensino Médio. Ter mais contato com outros textos, porque a gente fica muito focado em Enem e livro de material didático mesmo, só aprender a matéria e Enem, aprender a matéria e Enem. (...) e aí eu acho que então teria que ter um contato desde o Ensino Fundamental pra gente já ir acostumando com a linguagem e não chegar na Faculdade e não ficar, assim, apavorada. Nossa, é muito assustador quando você pega um texto e não consegue entender.

Diante do exposto, pode-se afirmar que todas essas percepções dos estudantes se aproximam do modelo de socialização acadêmica, já que este considera que as normas e técnicas devem ser aprendidas para que os alunos tenham acesso a toda a Instituição, como se essas técnicas fossem homogêneas. Considera-se como foco a orientação para a aprendizagem de aspectos formais e, por isso, não trata de questões discursivas da produção institucional. Esse modelo, em relação ao primeiro, é visto como um avanço, já que é um pouco mais sensível à individualidade dos estudantes, mas ainda não trata de aspectos mais contextuais, ideológicos.

Interessante notar que a aluna delega à escola a responsabilidade de ter contato com a escrita e leitura de diferentes gêneros acadêmicos "para ir acostumando" e não chegar à universidade despreparada. Menciona que o Ensino Médio é muito voltado para o Enem, o que acaba sendo restritivo. Embora não diga literalmente, podemos inferir que ela parece sentir falta de práticas sociais de leitura e de escrita a partir de diferentes gêneros e não apenas aqueles voltados exclusivamente ao treino da redação do Enem.

Ressaltamos também que, ainda nos dias de hoje, há uma grande ruptura entre as práticas de escrita no Ensino Médio e no Ensino Superior. Como a redação do Enem tem grande peso para a entrada nas universidades, boa parte das aulas de língua portuguesa no Ensino Médio tem se dedicado ao treino da redação, deixando de lado práticas sociais de escrita que tenham propósitos ligados a outras realidades sociais, históricas e culturais dos alunos. Podemos conjecturar que essa visão de escrita como treino de um modelo ensaístico está enraizado na concepção de escrita desses estudantes. Identificamos, portanto, uma necessidade de problematizar as atividades de escrita como uma prática social, como veremos a seguir.

\subsubsection{Letramentos Acadêmicos}

A expressão "letramentos acadêmicos" é usada em diferentes contextos com significados distintos (LILLIS; SCOTT, 2007). As autoras explicam que esses sentidos podem se referir a cursos de escritas com viés instrumental, cujo objetivo é inserir graduandos no meio acadêmico, ou podem significar uma visão ampliada das convenções textuais no Ensino Superior.

Neste trabalho, conforme já discutido, adotamos a concepção de letramentos acadêmicos como um campo de pesquisa aplicada com princípios epistemológicos e metodológicos próprios, com base nos Novos Estudos de Letramento. Portanto, essa categoria de análise envolve os preceitos teórico-metodológicos discutidos na parte teórica deste artigo.

Sendo assim, analisamos as entrevistas dos estudantes e encontramos poucos indícios dessa perspectiva:

ENTREVISTADORAS: você recebe retorno dos resumos que vocêfaz?

Estudante 1: a professora é a que mais está pedindo resumo ultimamente. A professora de gêneros literários pede mais é resenba. Mas a professora entrega o resumo que a gente fez e ela está aberta para conversar com a gente e ela deixa algumas anotações. E ela também, além disso, ela vê em que que a turma está com dificuldade e faz uma aula. No nosso caso ela até deu uma aula antes da prova, explicando a sumarização pra tentar ajudar a diminuir o texto da gente e ficar mais assertiva a mensagem que a gente tinha que passar. (Grifos nossos). 
ESTUDANTE 2: até então, a professora fez bastante correção, apontou algumas coisas, ela se tornou bastante acessível, então, en consegui conversar mais com ela a respeito disso.

Em suas respostas, os estudantes dão ênfase a determinadas atitudes da professora que deveriam ser consideradas corriqueiras numa sala de aula com mais equilíbrio nas relações de poder entre professores e alunos: abertura para conversar e aulas extras para dirimir dúvidas. Nesse sentido, os alunos parecem depreender as relações de poder que podem ser instauradas (ou não) com os professores e como isso pode resultar na qualidade do texto a ser produzido.

Essa percepção, inclusive, é marcada linguisticamente pelo estudante 1, quando inicia uma das frases utilizando o operador argumentativo "mas", que contrapõe um argumento orientado para conclusões contrárias e "até", que assinala o argumento mais forte de uma escala, o que pode indicar que em outras situações vivenciadas pelo aluno esses comportamentos docentes não eram comuns: "entrega o resumo", "está aberta para conversar" e "uma aula (de revisão) antes da prova". Notamos, porém, que essas importantes questões relacionadas a simetria de poder e autoridade na academia não foram exploradas pela professora da turma.

Conforme verificado, não detectamos, com tanta clareza, na fala dos estudantes, traços do modelo de letramentos acadêmicos tal como propusemos. Diante disso, duas hipóteses foram levantadas.

A primeira tem relação com os objetivos da disciplina:

- reconhecer, caracterizar e produzir resumos e resenhas;

- abordar e analisar projetos e artigos científicos;

- reconhecer a estruturação padrão e os modos de configuração de textos acadêmicos;

- identificar e utilizar as normas da ABNT para elaboração de textos acadêmicos, sobretudo o Trabalho de Conclusão de Curso (Dados retirados do site do curso, 2020, p. 42).

Como pode ser observado, os objetivos retirados do plano de ensino que consta no projeto pedagógico do curso de Letras da instituição focalizada abarcam, de modo geral, uma apresentação panorâmica de alguns gêneros acadêmicos, além de orientações relativas ao uso das normas da ABNT. Esses objetivos são compatíveis com disciplinas de caráter instrumental, ministradas no primeiro semestre letivo do curso, quando os alunos estão chegando à universidade e precisam participar de práticas de leitura e escrita de uma dada comunidade discursiva.

Mesmo sendo desenvolvida em um curto espaço de tempo (72h), consideramos que a referida disciplina, do modo como foi ministrada pela professora, representa um avanço, principalmente se compararmos com currículos de anos anteriores, em que não havia qualquer abordagem de gêneros acadêmicos ao longo do curso. Os alunos, muitas vezes, passavam pelo Ensino Superior sem orientações mais detalhadas sobre as convenções da escrita acadêmica. Como já mencionado, não consideramos nenhum dos modelos delimitados por Lea e Street (1998) como equivocados. São diferentes perspectivas de escrita que coexistem no contexto acadêmico.

A segunda hipótese para justificar o apagamento da perspectiva do modelo de letramentos acadêmicos nas entrevistas é que esses letramentos não se manifestam de forma pontual, em um período específico ou em uma determinada disciplina. Ao contrário, constituem-se como parte de um processo que nunca se finda: as práticas de letramentos vão se desenvolvendo e se ressignificando ao longo da trajetória de vida dos sujeitos. Por isso, no contexto das entrevistas, talvez não tenha sido possível detectar, com muita clareza, por exemplo, como as relações de poder se manifestam na visão desses estudantes do primeiro semestre e como suas questões identitárias estavam sendo constituídas ao longo das atividades desenvolvidas nas aulas.

Em suma, as análises das entrevistas dos estudantes nos conduziram ao entendimento de que ainda continuam prevalentes as visões de habilidades de estudos e socialização acadêmica, em comparação com a perspectiva dos letramentos acadêmicos, sejam quais forem as razões para isso. De qualquer modo, para o estudante, "sua inserção nas práticas e eventos de letramento que cercam o discurso acadêmico será um fator decisivo para a construção da sua identidade como participante legítimo e legitimado do ambiente acadêmico" (BEZERRA, 2015, p. 65-66) e isso só será possível, de fato, quando as três abordagens passarem a ser desenvolvidas de modo complementar nas universidades.

Isto posto, passamos, a seguir, à análise da entrevista com a professora. 


\subsection{Análise da entrevista com a professora}

Como poderá ser notado na análise a seguir, durante a entrevista, a professora oscila entre os diferentes modelos de letramentos propostos por Lea e Street (1998) ao falar sobre o resumo, ora enfatizando aspectos mais formais e estruturais, ora se preocupando em atender às convenções próprias do gênero na área de conhecimento específica (Letras), ora revelando uma atenção especial à questão do gerenciamento de vozes.

ENTREVISTADORAS: Você pode especificar como você trabalba o resumo? Conta pra gente como você dá o resumo.

PROFESSORA: Eu trabalho o resumo, em geral, en começo com um texto da área deles, então, na área de Letras, por exemplo, que foi feito com os alunos, e nós vamos fazendo uma seleção das informações principais.

Nota-se aqui, de início, a preocupação da professora em abordar um texto da própria área acadêmica dos alunos, o que podemos associar à visão do modelo de socialização acadêmica. Continua:

PROFESSORA: Num dado momento, eles vão fazendo o que a gente chama de esquema, que é mais ou menos um mapa mental do texto (...). Eu sempre falo com eles que eles precisam trabalbar o objetivo do texto, os teóricos principais que estão presentes, pensando nesse resumo acadêmico da área de Letras. Que conceitos importantes são trabalbados e que vão constar no resumo deles, se bá alguma análise, algum resultado ou alguma constatação importante a partir daqueles conceitos e uma síntese dos resultados e de como que eles vão concluir ali, como que o autor conclui aquele texto ali. Então eles precisam fazer com as palavras deles, sempre pensando assim. Lembrando que, no meu caso, como eu trabalho redação acadêmica, eu sempre peço para eles utilizarem a linguagem acadêmica. Eles vão precisar, por exemplo, fazer citações ao texto-base.

Há diversos elementos a serem analisados no trecho acima. A preocupação com a área de Letras se manifesta novamente. Em outro momento da entrevista, a professora diz que a questão do preconceito linguístico surgiu na turma e ela, assim, decidiu levar um texto sobre esse tema, o que confirma um olhar direcionado para o campo disciplinar e para as demandas dos estudantes. A abordagem do gênero fica fortemente relacionada à organização retórica do texto, a determinados movimentos retóricos que os alunos deveriam seguir, como "objetivo do texto" e "síntese dos resultados". A dimensão linguístico-textual também é contemplada na preocupação com a "linguagem acadêmica", ficando obscurecida, aqui, a sua dimensão sociocultural.

Sobre a dimensão sociocultural do resumo acadêmico, chama a atenção, no excerto a seguir, a forma como a professora define para os alunos os propósitos comunicativos do gênero:

ENTREVISTADORAS: Você costuma especificar os propósitos quando você solicita a escrita de resumo? Você fala com eles pra que eles vão fazer?

PROFESSORA: Eu sempre falo: para quê e pra quem? Eles precisam ter um propósito para escrever e precisam ter um leitor especifico, mesmo que esse seja o professor.

Podemos observar que, embora se fale em ter um objetivo delimitado para a escrita do resumo, não se leva em conta como esse gênero circula socialmente, uma vez que se pode inferir que um objetivo aceitável é que o aluno produza o resumo unicamente para ser avaliado pelo professor. Na sua vida acadêmica, em suas práticas de letramentos, com que finalidade um aluno efetivamente escreve um resumo? Não seria razoável supor que, se não fosse apenas para cumprir uma tarefa, o aluno, via de regra, resumiria um texto para si próprio, para fins de estudo, embora sejam possíveis outros leitores? É importante que se pense no destinatário previsto, no lugar social do destinatário, mas considerar somente o professor nesse papel é aproximar-se da visão de habilidades de estudos.

A professora, em alguns excertos da entrevista, no entanto, parece aproximar-se do modelo de letramentos acadêmicos ao levar em conta a complexidade envolvida na retextualização presente no resumo acadêmico, no gerenciamento de vozes, o que tem uma relação estreita com as relações de poder na Academia:

ENTREVISTADORAS: E pela sua experiência, quais são as maiores dificuldades que os alunos têm na produção do resumo?

PROFESSORA: Eles têm dificuldade de transformar a fala dos autores nas palavras deles. Eles têm dificuldade com paráfrase. Eles costumam muito copiar (...). 
Como se percebe, a professora não apenas faz referência à necessidade de o autor usar as próprias palavras, mas de "transformar as palavras do autor nas palavras deles", o que pode sugerir uma ideia de apropriação e empoderamento. Por outro lado, a entrevista como um todo revela um alinhamento com o modelo de habilidades de estudos. A questão da retextualização, por exemplo, é vinculada à ideia de "paráfrase", aparecendo com um dos parâmetros privilegiados de avaliação dos resumos:

ENTREVISTADORAS: Que critérios de avaliação você utiliza para os resumos?

PROFESSORA: Eu utilizo no primeiro momento a estrutura, se ela foi construída. Num segundo momento, se as informações principais a respeito de conceito, por exemplo, estão presentes e, num terceiro momento, se eles conseguiram levar a paráfrase de maneira adequada ou se eles simplesmente não reproduziram a informação do texto. (Grifo nosso).

PROFESSORA: Eu sempre trabalho com eles a produção de citação direta e indireta, porque aí a situação indireta eles precisam constar o que de mais importante tem. Eaí eles pelejam com a paráfrase. (Grifo nosso).

A professora parece manter em foco o conceito de paráfrase, mais relacionada a aspectos de ordem linguísticotextual. Ao lado desses fatores, seria também desejável que ela explorasse os componentes sociodiscursivos dos quais o texto emerge, ligados "tanto à construção do quadro interlocutivo, isto é, à assunção, pelos sujeitos, de lugares e papéis sociais, à delimitação de propósitos comunicativos e do espaço e tempo da interação, quanto aos mecanismos enunciativos, portanto, à diafonia, à polifonia e à modalização" (MATENCIO, 2002, p. 111).

O que entra em cena, no caso da retextualização, é que essa atividade envolve práticas discursivas acadêmicas que englobam o saber-fazer e também o saber-dizer (MATENCIO, 2002). Assim, os alunos podem descobrir e se apropriar de determinadas práticas sociais que envolvem os processos de escrita próprios do domínio científico e que só são evidentes para os membros mais experientes.

\section{CONSIDERAÇÕES FINAIS}

Muitas vezes, tem-se a expectativa de que os estudantes já cheguem à universidade demonstrando familiaridade com os gêneros acadêmicos, como se já tivessem apreendido o uso desses gêneros de forma sistemática na Escola Básica. Com este trabalho, fica claro que, mesmo com relação a um gênero bastante recorrente nas práticas escolares, que é demandado para fins de estudo e pesquisa em sua vida cotidiana, o aluno começa seu percurso no Ensino Superior com visões um tanto limitadas ou até equivocadas sobre o que realmente é importante no ato de resumir textos acadêmicos.

Em nossas reflexões sobre concepções que subjazem ao ensino-aprendizagem de escrita acadêmica, vimos que esse conhecimento não se dá espontaneamente. O processo de escrita de um resumo acadêmico envolve múltiplas dimensões (linguístico-textual, sociodiscursiva) e pode-se assumir diferentes modelos de escrita (habilidades de estudos, socialização acadêmica, letramentos acadêmicos), não se tratando, portanto, de algo trivial.

Nas entrevistas com os alunos, vimos que predominou o modelo de habilidades de estudos. Há uma grande preocupação, por parte deles, com aspectos estruturais e formais, possivelmente consequência de uma visão mais prescritiva que tradicionalmente assume a Escola Básica, com a normatização excessiva de uma dada configuração textual. No entanto, há também a percepção clara de que precisam se apropriar desse conhecimento para que possam se integrar plenamente ao contexto acadêmico, o que já os aproxima bastante também do modelo de socialização acadêmica.

No que diz respeito à professora da turma, vimos que seu discurso ora tende mais para um tipo de modelo, ora tende mais para outro. Embora haja a preocupação de orientar os alunos na escrita acadêmica de forma mais sistemática, de acordo com as convenções desse contexto universitário, os dados evidenciaram que não se faz notar ainda uma apropriação do modelo de letramentos acadêmicos no processo de ensino-aprendizagem do gênero resumo. Conforme discutido, tal modelo não negligencia o estudo da língua, da gramática, da semântica ou da pontuação, por exemplo, não deixa de ensinar sobre a composição textual do gênero e considera a relevância da socialização no ambiente acadêmico, mas vai além: concebe a escrita como uma prática social em que nem todas as dimensões são transparentes por envolverem questões de identidade, de autoria e de relações de poder na Academia. 
Mesmo quando se dialoga com as vozes de terceiros, o que se dá muito fortemente no caso do resumo acadêmico, quem escreve quer fazer ecoar a sua própria voz.

A própria existência de disciplinas/cursos voltados ao ensino de gêneros acadêmicos na educação superior nos primeiros semestres letivos, até em Cursos da área de Letras, como vimos neste estudo, aponta para o fato de que não se pode supor que os estudantes cheguem à universidade sabendo manejar esses gêneros, ou seja, os gêneros acadêmicos precisam, efetivamente, ser tomados como objetos de ensino, num processo contínuo de letramento. E o que os dados demonstraram muito bem é que tanto professor quanto estudantes precisam ter clareza de que escrever um resumo acadêmico não se trata apenas de um exercício de organização retórica ou de domínio das normas da ABNT. Diferentes aspectos estão envolvidos no processo da escrita, desde os propósitos até o estudo de unidades linguísticas, e demandam, sim, ensino situado e sistemático.

\section{REFERÊNCIAS}

BAKHTIN, M. (1952). Estética da Criação Verbal. São Paulo: Martins Fontes, 1992.

BEZERRA, B. Letramentos acadêmicos e construção da identidade: a produção do artigo científico por alunos de graduação. Linguagem em (Dis) curso - LemD, Tubarão, SC, v. 15, n. 1, p. 61-76, jan./abr. 2015.

BEZERRA, B. Letramentos acadêmicos na perspectiva dos gêneros textuais. Fórum Linguístico, Florianópolis, v. 9, n. 4, p. 247-258, out./dez. 2012.

BOTELHO, L. S.; FARIA; SILVA; DAMASCENO-MORAIS. (2018). Letramentos e formação inicial docente: iniciação à pesquisa científica. In: CADILHE, GARCIA-REIS, MAGALHÃES. Formação docente: linguagens, práticas e perspectivas. Campinas: Pontes Editores.

BOTELHO, L. S.; SILVA, M. C. (2014). O gênero monografia em um curso de Pedagogia: um estudo exploratório. In: APARÍCIO, A. S. e SILVA, S. (Orgs) Gêneros textuais e perspectivas de ensino. Campinas: Pontes.

CAETANO OLIVEIRA, M. de C. (2020). A produção de resumos acadêmicos: um estudo preliminar sobre a usabilidade do software "AutorlA - meu resumo". Fólio - Revista de Letras, Vitória da Conquista, v. 12, n. 1, jan./jun.

CELANI, M. A. (2005). Questões de ética na pesquisa em Linguística Aplicada. Linguagem \& Ensino, Pelotas, v. 8, n. 1, p.101-122.

FIAD, R.(Org.) (2017). Letramentos Acadêmicos: contextos, práticas e percepções. São Carlos, SP: Pedro \& João Editores.

LEA, M. (2006). Explorando abordagens linguísticas à aprendizagem e avaliação online. In: SILVA, M. e SANTOS, E. (Org.). Avaliação da aprendizagem em educação online. São Paulo: Edições Loyola.

LEA, M.; STREET, B. (2014). O modelo dos letramentos acadêmicos: teoria e aplicações. Tradução de Komesu e Fischer In: Revista da USP. v. 16, n. 2, p. 477-493, jul./dez. Disponível em: <http://www.revistas.usp.br/flp/article/viewFile/79407/ pdf_20>. Acesso em: 30 jan. 2015.

LEA, Mi STREET, B. (1998). Student writing in Higher Education: an academic literacies approach. Studies in Higher Education, Jun, Vol. 23 Issue 2, p. 157-172.

LILLIS, T.; SCOTT, M. (2007). Defining academic literacies research: issues of epistemology, ideology and strategy. Journal of Applied Linguistics, v. 4, p. 5-32, jan. Disponível em: https://www.researchgate.net/publication/42798579_Defining academic_literacies_research_Issues_of_epistemology_ideology_and_strategy. Acesso em: 06/05/2019.

MACHADO, A. R. (Coord.); LOUSADA, E.; ABREU-TARDELLI, L. S. (2004). Resumo. São Paulo: Parábola.

MACHADO, A. R. (2002). Revisitando o conceito de resumos. In: DIONÍ́SIO; A. P.; MACHADO, A. R.; BEZERRA, M. A. (Orgs). Gêneros textuais e ensino. Rio de Janeiro: Lucerna. p. 139-150. 
MATENCIO, M. (2003). Referenciação e retextualização de textos acadêmicos: um estudo do resumo e da resenha. Projeto Letramento Temático Letramento do Professor, Campinas, p. 1-11, 2003. Disponível em: file:///G:/PÓSDOUTORADO/ Projeto\%20Software\%20hipermidia\%20para\%20resumos/Referencial\%20teórico/Textos\%20a\%20ler/Referenciacao_e_ retextualizacao\%20(Matencio,\%202003).pdf>. Acesso em: 8 abr. 2019.

MATENCIO, M. (2002). Atividades de retextualização em práticas acadêmicas: um estudo do gênero resumo. Scripta, Belo Horizonte, v. 6, n. 11, p. 25-32.

MOTTA-ROTH, D. (2000). Tese de Doutoramento. Rbetorical features and disciplinary cultures: A genre-based study of academic book reviews in linguistics, chemistry, and economics. In: V. J. LEFFA (Compilador). Pelotas, RS: UCPEL. ISBN 85-7590-006-4. Pelotas, RS: UCPEL.

NASCIMENTO, M. I. (2005). A produção do gênero resumo. 144p. Dissertação de Mestrado. Programa de Pós-Graduação em Letras. Universidade Federal de Pernambuco, Recife.

PASQUOTTE-VIEIRA, E. A. (2014) Letramentos Acadêmicos: (re)significações e (re)posicionamentos de sujeitos discursivos. Tese de Doutorado - Instituto de Estudos da Linguagem, Universidade Estadual de Campinas, Campinas.

RUSSELL, D.; LEA, M.; PARKER, J.; STREET, B.; DONAHUE, T. Exploring notions of genre in 'academic literacies' and 'writing in the disciplines': approaches across countries and contexts. In: BAZERMAN, BONINI; FIGUEIREDO (Ed.). Genre in a Changing World. Perspectives on Writing. Colorado: The WAC Clearinghouse and Parlor Press. http://wac.colostate. edu/books/genre/, 2009.

STREET, B. (2014). Letramentos sociais: abordagens críticas do letramento no desenvolvimento, na etnografía e na educação. São Paulo: Parábola.

STREET, B. (2010a). Academic Literacies approaches to genre? Revista Brasileira de Linguística Aplicada, Belo Horizonte, v. 1, n.2, p.347-362.

STREET, B. (2010b). Dimensões "escondidas" na escrita de artigos acadêmicos. Tradução Silveiro e Fischer. Perspectiva, Florianópolis, v.28, n 2, p. $541-597$, jul/dez.

STREET, B. (2003). What's 'new' in New Literacy Studies? Critical approaches to literacy in theory and practice. Current Issues in Comparative Education. 5(2) May 12, P. 77-91.

STREET, B. (1984). Literacy in Theory and Practice. Cambridge: Cambridge University Press.

Recebido: 13/8/2020

Aceito: 19/3/2021

Publicado: 5/7/2021 